\title{
THE ACCULTURATION ORIENTATION OF INTERNATIONAL STUDENT CENTRES ANALYSED USING BOURHIS' INTERACTIVE ACCULTURATION MODEL (IAM)
}

\section{BY}

Kathryn Maria Deckert,

BA University of Waterloo, 2008

BED University of Toronto, 2013

A Major Research Paper

presented to Ryerson University

in partial fulfillment of the requirements for the degree of

Masters of Arts

in the program of

Immigration and Settlement Studies

Toronto, Ontario, Canada, 2020

(C) Kathryn Deckert, 2020 


\section{Author's Declaration}

I hereby declare that I am the sole author of this Major Research Paper. This is a true copy of the $\mathrm{MRP}$, including any required final revisions, as accepted by my examiners.

I authorize Ryerson University to lend this MRP to other institutions or individuals for the purpose of scholarly research

I further authorize Ryerson University to reproduce this MRP by photocopying or by other means, in total or in part, at the request of other institutions or individuals for the purpose of scholarly research.

I understand that my MRP may be made electronically available to the public.

Kathryn Deckert 


\title{
THE ACCULTURATION ORIENTATION OF INTERNATIONAL STUDENT CENTRES ANALYSED USING BOURHIS' INTERACTIVE ACCULTURATION MODEL (IAM)
}

\author{
Kathryn Maria Deckert \\ Master of Arts, 2020 \\ Immigration and Settlement Studies, Ryerson University
}

\begin{abstract}
This paper uses Bourhis' Interactive Acculturation Model (IAM) to analyse the type(s) of dominant host acculturation orientation(s) espoused by the International Student Services Offices at the University of Toronto, York University, and Ryerson University through their International Student Services webpages. The multilevel structure of the IAM model allows the researcher to consider the multiple spheres in which the students exist: macro level government policy, the city in which the university is located, their experience on campus. To guide this analysis, the researcher followed a thematic constructionist approach to capture important content from the data that could be used to respond to this question. After the coding process five key themes were identified based on their prevalence in the data and their utility in answering the research question (Braun and Clark, 2006). The host orientation of all three International Student Services webpages is found to be predominantly one of integration.
\end{abstract}

\section{Key words:}

The acculturation orientation of international student service centers' websites, key words: international students; international student service centres; Canada; Acculturation. 


\section{Table of Contents}

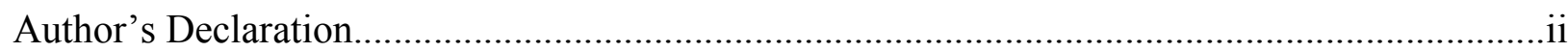

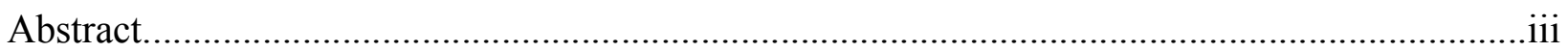

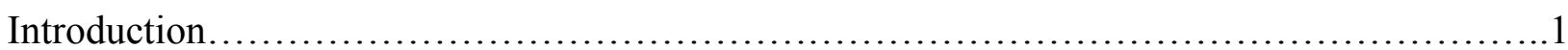

The Economics and Scale of International Education ....................................................... 1

The Political Underpinnings of International Education ....................................................2

Leading Acculturation Models and Their Utility in Examining the Role of International

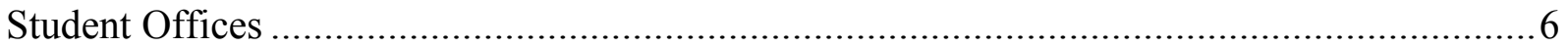

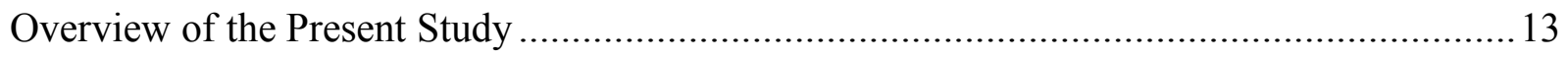

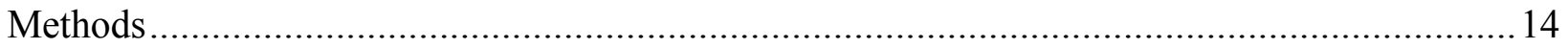

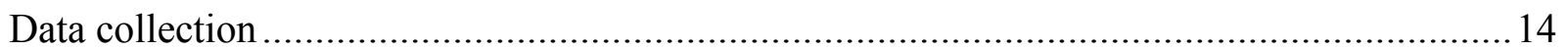

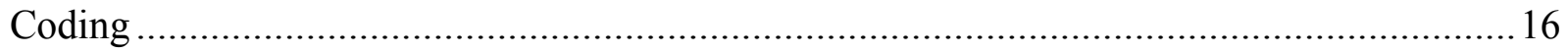

Operationalising Bourhis’ Dominant Host Majority Acculturation Orientations ..................... 16

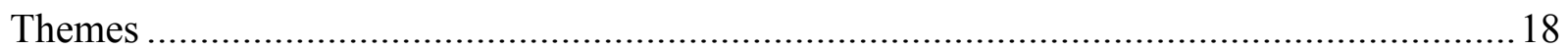

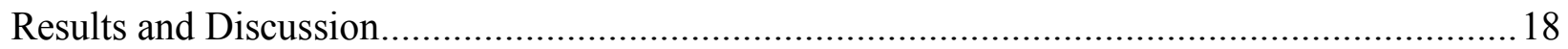

Theme 1: Connecting International Student to each other and/or Canadian Students .............. 18

Theme 2: State Immigration Policies As They Pertain to International Students ....................26

Theme 3: How are potential problems acknowledged and/or addressed..............................28

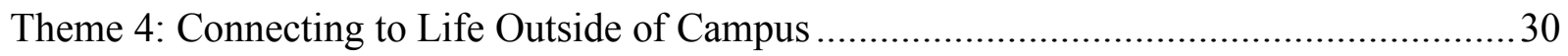

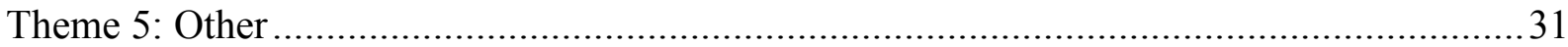

Words Chosen to Describe the Programming of International Student Service Websites ........33

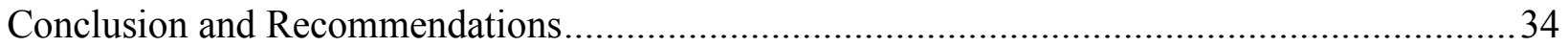




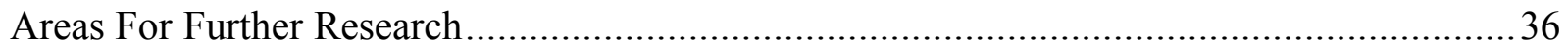

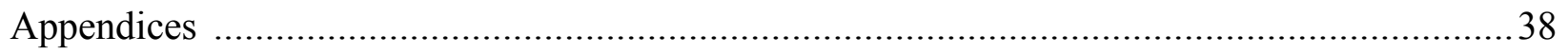

Figure 1Bourhis' Model............................................................. 41

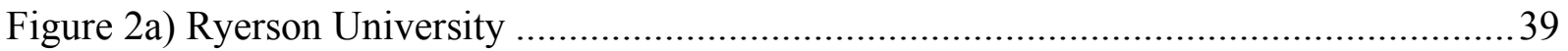

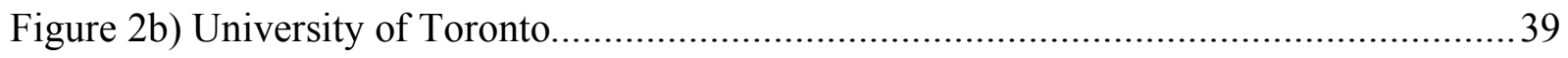

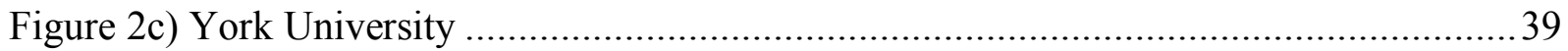

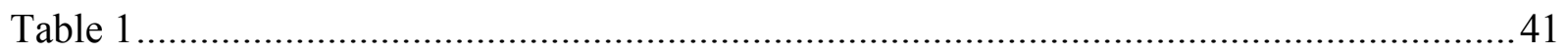

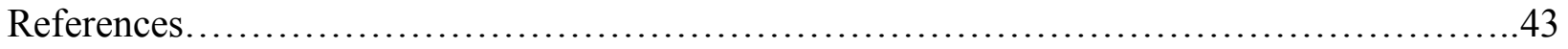




\section{The Acculturation Orientation of International Student Centres Analysed Using Bourhis' Interactive Acculturation Model (IAM)}

With a history of renowned scholars crossing international boundaries in search of knowledge and collaboration, academia has long been an international pursuit. However, the growth in the rate of students seeking an international education, coupled with increasing international student fees has transformed the field of international education. In the last two decades, international education has changed from a people-centred movement based on the exchange of ideas into a multi-billion dollar export industry linked to profit and permanent resettlement (Altbach, 2015; Ziguras, 2006). In response, International Student Offices, the first of which appeared at the University of Toronto in 1950, have grown in their importance and prominence on campus, and in the breadth and depth of services that they provide (Cameron, 2006; Patton and Hannon, 2008). While governing state bodies may hold a macro lens over the inclusion and utility of international students in nation building, it is the universities themselves that provide international students with acculturation services through their International Student Offices. This paper seeks to determine the acculturation orientation of the International Student Service Websites of the University of Toronto, York University, and Ryerson University. Before these International Student Offices are examined, reviewing the broader context of international education through the economic implications and policy initiatives impacting the field will help to situate this research.

\section{The Economics and Scale of International Education}

In the 2014-2015 academic year, "international students brought $\$ 27$ billion to the US economy" (Cantwell, 2015 p.514). In Canada, a country eight times smaller than the United States, the proportional impact on the country's economy is even larger. The Canadian Federal 
Government reports that the economic impact of hosting international students in Canada is " 11 billion annually, with about 5.4 billion of that spent in Ontario" (Crawley, 2017). Furthermore, the Federal Government includes international students under inputs that contribute to Citizenship and Immigration Canada's (CIC) Strategic Outcome 1, which is "Migration of permanent and temporary residents that strengthens Canada's economy (CIC, 2015, p. 7). CIC has since been renamed Immigration, Refugees and Citizenship Canada (IRCC). The contribution of international students to Canada's economy is significant. In fact, on a global scale, Canada holds a large share of the international student market. In 2017, Canada moved ahead of Australia and France to become the $4^{\text {th }}$ ranked host destination in the world with one of the most diverse student bodies- including students from 186 countries (CBIE, 2018). By 2018, Canada hosted 572,415 international students at all levels of study according to the Canadian Bureau for International Education (CBIE).

In addition to the macro economic impact, individual post-secondary institutions have grown reliant on international student fees for their general operating budgets (Cantwell, 2015). At the University of Toronto, as of the 2017-2018 fiscal year, international students now contribute more than half of the university's $\$ 1.3$ billion in tuition revenue (Crawley, 2017). To put this into perspective, between 2010 and 2018 there was a 154\% increase in international students in Canada; this growth trend shows no sign of slowing (IRCC, 2019).

\section{The Political Underpinnings of International Education}

The continued growth of the international education sector is tightly connected to the willingness of the Federal Government to continue to provide study permits and temporary visas that allow international students to enrol and attend classes at the schools that send them offers of admission. As explained in Citizenship and Immigration Canada (CIC) documents, CIC defines 
its role in regards to international students as, "responsible for facilitating the entry of international students to Canada for study purposes" (CIC, 2015). And yet, the state's jurisdiction over a country's border is not universally accepted (Bauder, 2014; Nyers, 2003). For example, the action of a migrant crossing a border irregularly often invokes comments that they should instead, 'follow due process' (Nyers, 2003). For an international student unable to receive a study permit and visa, an irregular border crossing is the only way to attend the school to which they received an offer of admission. Honig reframes this potential act of irregular border crossing, not as an illegal act threatening the sovereignty of a nation but as an action in which the migrant is, "taking rights and privileges rather than waiting for them to be granted by a sovereign power", and that in doing so the act is, "a quintessentially democratic practice" (Nyers, 2003, p. 1077). It is this belief in open borders that spurred some universities to counter the state control of accessibility to international education by becoming sanctuary universities. As such, they have programming which allows international students to attend regardless of their legal standing within the country. York University has become the first school in Canada to give undocumented people living in Canada the opportunity of attending University classes (Wiens, 2018).

In Canada, the Federal Government in partnership with post-secondary institutions, is keen to continue to permit the entry of international students that it deems to be of benefit to the country. The Federal Government states that, "International students provide social and economic benefits to the education sector as well as the communities in which they reside" (CIC, $2015, p .7)$. The inclusion of the word social is meaningful. International students, who previously were studied as sojourners, have not received much attention regarding their social impact on their host country. This notion of temporary and therefore, 'no impact presence' is no longer accepted. As noted during a Department for Business, Innovation and Skills Committee 
meeting in the United Kingdom, in reference to international students, "the idea that somebody can be here for three, four, five years or longer but in some way do not have an impact is absurd"” (Jodi, 2018).

The Federal Government is actively monitoring and adjusting the international education sector. It has recently put measures in place to prevent cases of immigrant fraud in the study permit category by creating Designated Learning Institutes (CIC, 2015). As of February of 2019, the Federal Government announced through a program delivery update, that it was making changes to its Post-Graduation Work Permit Program (PGWPP) (Government of Canada, 2019). PGWPP is significant to international students as it provides recipients with open work permits allowing them to seek work in Canada without requiring a job offer at the time of application, to switch employer at any time, and to remain in Canada for a period of up to three years following graduation (Government of Canada, 2019). Additionally, if the work experience gained through the PGWPP is in level A, B or O under Canada's National Occupational Classification (NOC) international students will have a better chance of qualifying for permanent residence in Canada through the Canadian Experience Class. The recent changes to the PGWPP include lengthening the time after graduation that an international student can apply for a PGWPP from 90 days to six months and changing eligibility criteria to allow international students who needed to take a leave of absence during their degree for an allowable reason to qualify for a PGGWP (CIC, 2015).

According to the 2018 CBIE student survey, $60 \%$ of international students plan to apply for permanent residence after graduation (CBIE, 2018). This dream is much more plausible with the acquisition of the previously mentioned Canadian Work Experience Class as it carries significant weight in the permanent residency application process. By 2018, "more than 570,000 
people held valid permits to study in Canada and more than 130,000 people held a valid PostGraduation Work Permit” (Toughill, 2019). The Canadian government considers international students to be model immigrants poised to provide Canada with skilled labour and population growth. In 2017, 10,950 previous study permit holders became permanent residents, a marked increase from prior years (IRCC, 2018). Further evidence of Canada's desire to retain international students is the expansion of the Study and Stay Program, which strengthens the odds of an international student who attends a college or university in Atlantic Canada being granted the status to remain Canada after the completion of the program. In addition to providing post- graduation employment supports, the program aims to recruit and retain international students to the maritime provinces creating, "inclusive growth where newcomers are welcomed, celebrated and supported.” (Atlantic Canada Opportunities Agency, 2018).

This continued government support of the international education sector through programs permitting the entry of international students into the country is crucial. In the United States, colleges and universities fear that their current government's isolationist tendencies may wreak havoc with their international student revenue streams. The financial impact of a visa ban to their top sending countries could destroy a university financially. In response to this perceived risk, the University of Illinois at Urbana- Champaign, took out a risk policy to guard against such an eventuality. The school pays $\$ 424,000$ annually for up to $\$ 60$ million in coverage that "will pay out a claim if a specific incident - a visa ban because of a government action, for example — causes the number of Chinese students in the colleges of business and engineering to decline by 18.5 percent over a 12-month period" (New York Times, 2019). If Canada were to limit the movement of people across their border the impact on the field of international education would likewise be dire. It is not always the host country that limits access of international post- 
secondary institutions to international students. Political disputes can also result in a foreign government recalling their international students from Canada. This underscores the importance of diversifying the sending countries that Canada partners with to recruit International students (Blatchford, 2018). Canada's 2018 dispute with Saudi Arabia which resulted in Saudi international students being called on by their own government to leave Canada is one such example.

\section{Leading Acculturation Models and Their Utility in Examining the Role of International Student Offices}

In recent years, researchers have paid more attention to the acculturation experiences of international students (Burger, 2018; Cantwell, 2015; Gregory, 2018; Lee, 2007). The research tries to fill in the gaps in knowledge surrounding the diverse experiences of international students, who were often previously examined as a homogenous group. However, most of the academic discourse continues to revolve around isolating and examining what are termed to be acculturation stressors. The most common of these stressors referred to in the literature are: language barriers, loneliness, and difficulties in adjusting to new living and academic environment (Berger, 2018; Lee and Rice, 2007; Smith and Khawaja, 2011).

In their 2011 Review of the Acculturation Experiences of International Students, Smith and Khawaja call for further research on the way host culture impacts the acculturation experience of international students. To help answer this question, this paper seeks to determine the acculturation orientations of the International Student Offices serving the University of Toronto, Ryerson University, and York University.

The term, "acculturation," in reference to a psychological phenomenon, was first used by Graves in 1964 when he coined the term, "psychological acculturation" to describe the change 
individuals experience as their cultural group changes around them because of contact with another culture (Bourhis et al, p. 370). In practice, this unidirectional understanding of acculturation occurred during a time when the hoped for outcome of acculturation was assimilation. Peer reviewed articles from the 1960s demonstrate that during this time period, the terms acculturation and assimilation could almost always be used interchangeably. Analysing the degree to which a person acculturated was the same as studying the degree to which they assimilated. Acculturation during this time period included the forced assimilation of First Nations people in Canada through the residential school system and the acceptance of new immigrant groups, to the degree to which they assimilated.

As the global movement of people rose, the study of acculturation received more attention and new models began to account for more complexity in the psychological and behavioural changes taking place as people experienced prolonged intergroup contact. Berry, whose model is still most frequently used by researchers studying acculturation, developed a new conceptual model of acculturation which he believed to be applicable to immigrants, sojourners, and refugees (Berry, 1997). Berry specifically notes that international students are part of the sojourner group because of the temporary nature of their stay in the host country. Berry's model posed two questions of the immigrant resulting in one of four possible acculturation attitudes: integration, assimilation, separation, and marginalization (Ward and Kus, 2012, p.472). The two questions concerning cultural maintenance and cultural contact were,

1) Is it considered to be of value to maintain one's identity and characteristics, and 2) Is it considered to be of value to maintain relationships with larger society (Berry p.10). 
Although Berry's model indicates that the acculturation strategies of both the dominant and nondominant groups needed to be determined, in practice, researchers often only studied the acculturation of the immigrant and not the host. Researchers would slot the immigrant into the non-dominant side of the acculturation process model which allowed for four possible outcomes to apply: Integration applies when individuals strive to maintain their heritage culture in addition to intentionally interacting with people in the host culture, Assimilation applies when individuals do not want to maintain their cultural identity and do want to interact with the host culture, Separation applies when individuals value and maintain their heritage culture and avoid interacting with the host culture, and Marginalization applies when there is low cultural maintenance (often for reasons of enforced cultural loss), and little interest in having relations with others (often for reasons of exclusion or discrimination) (Berry, 1997).

The central critique of Berry's (1997) acculturation model is that it does not easily account for the impact of the host majority's attitude and behaviour on the immigrant. That is, even if a new immigrant wanted to take on an acculturation attitude of integration they would be unable to if the host society did not permit them to join. While the model was originally developed to be applied to both the host and the immigrant, it failed to highlight how the interaction of these groups' potentially differing orientations could impact one another's experiences.

Berry did modify his 1997 model to indicate that the researcher must include the question, "of whether the minority groups are permitted the option of answering the first two questions?" (Ward and Kus, 2012, p.473). Despite the modification, the model continued to be used by academics and practitioners in its original form, and usually only to assess the minority culture, or immigrant's acculturation. In the Applications section of his 1997 model, Berry notes 
that, "perhaps most important is the advocacy of the view that acculturation involves mutual accommodation" (Berry, 1997 p.28). While Berry created a model that is frequently used to identify and predict the acculturation attitudes of migrants, he was clear in his belief that the preferred societal model was pluralistic in nature, thereby requiring an integration attitude on the side of the host and migrant (Berry, 1997).

In 2009, Chirkov challenged the academy via a paper criticizing the lack of culture and psychology present in Berry’s acculturation model (Chirkov). Chirkov described how psychologists were evaluating the acculturation of immigrants by operationalizing culture as an individual's ethnicity and/or nationality. His concern was that tying culture to either of these traits was misguided as modern anthropology views culture not as an externally imposed phenomenon but as a, "construct that is both self and other imposed" (Chirkov, 2009). He argues that a researcher must look at the meaning of actions to understand them- focusing on both the internal and external motivations impacting the immigrant. In seeking to address this absence of culture within acculturation models he developed the Theory of Socio Cultural Models (TSCMs) in 2019 (Chirkov).

Applying Chirkov's SCMs to the experience of international students would be an intensive but possibly fruitful endeavour. Since the model requires an understanding of many layers of experience, personal interviews would be conducted, as well as an analysis of the ways in which an individual's heritage culture and host culture impacted their acculturation experience. Since Chirkov is careful to note that culture is not tied to nationality, the analysis would need to include a localised review of the specific socio-political and familial context in which the immigrant was raised. It would also need to include an assessment of the localized culture of the community in which the international student attends school and possibly settles. 
While the narrative that emerges from this experience would likely be illuminating, it would be immensely time consuming to perform this for one international student let alone a group of international students with differing backgrounds. Furthermore, this paper strives to isolate and assess the role of the host society as it is represented by the international student office and Chirkov's model does not seem to be readily applicable. While the consideration of this model adds to the contextual narrative of the immigration experience in which International Student Services Offices operate, it is too complex and not well matched to the focus of this paper.

In the same year that Berry's acculturation model was introduced, Bourhis created the Interactive Acculturation Model (IAM). The IAM accounts for more variables than Berry's model, offering a bird's eye view of a broader experience of acculturation (see Figure 1). But it does not require narrative accounts like Chirkov's SCM model. The IAM model considers the host culture, the individual immigrant, and their setting as they are interwoven into the process of acculturation.

The shapes Bourhis used to create the model presents the viewer with two distinct layers distinguished as boxes, with the larger upper box containing the factors that work together to create the resulting lower box that presents the possible outcomes of a multicultural society. The upper box contains not only the host and immigrant orientations, but also government decision makers, government policies, state agencies dealing with immigration and integration, and the resulting state integration policies that are shown to directly feed into the host and immigrant acculturation orientation boxes. While this model offers a visual representation of the shifts that occur at all levels of a society experiencing acculturation, its smaller boxes also allow researchers to isolate variables like host orientation. Additionally, the bidirectional flow of the feedback loops impacting their various sectors of society show that acculturation is a continuous 
and non-linear process. For the purpose of this paper, which is to examine the acculturation orientation of International Student Offices, this model enables the researcher to consider external factors impacting the development of the host orientation, while providing enough detail to concentrate on identifying the orientation. Bourhis' model offers a compromise between the simplicity of Berry's model and the denseness of Chirkov's model.

The goal of IAM is, "to present a non-determinist more dynamic account of immigrant and host community acculturation in multicultural settings.” (Bourhis et al, 1996 p. 379.) The model accomplishes this by measuring the host and immigrant acculturation orientations and then compares the resulting acculturation attitudes to decipher what outcome is produced. The three possible outcomes of the interaction between host and migrant acculturation orientations are consensual, problematic, and conflictual relationships (Bourhis, 1997). The four possible orientations of the host that contribute to these outcomes are:

Integration: Immigrants are welcomed into the host culture without needing to abandon their heritage culture. The Host celebrates and sees the value in the heritage culture of the immigrants, but the immigrants also incorporate important aspects of the host culture. This orientation believes that if immigrant groups adopt a stable biculturalism, they will eventually be able to contribute to the cultural pluralism that characterises the host society and as such become full members of the society (p. 380).

Assimilation: The immigrant is expected to relinquish their heritage culture and instead adopt the host's culture. If this process is completed, immigrants will be accepted as full members of the host society (p. 380). 
Segregation: The host community does not wish to be transformed by the immigrants living in their midst and for this reason wishes to maintain a physical distance from them (p. $380)$.

Exclusion: The host does not believe that immigrants will ever be fully able to relinquish their heritage culture nor do they believe that immigrants should be allowed to maintain their heritage culture. People who believe in this model not only want immigration to stop but they are willing to go so far as to deport previous immigrants whose presence within their culture is seen as abhorrent (p. 381).

Individualism: Individuality is more important than group membership. Individual character traits are what is important, not whether a heritage culture is kept or abandoned or whether a host culture is ignored or joined (p.381). The model does not elaborate on whether some character traits are acceptable while others are not.

By considering the different levels of a society as they are impacted by government policies, Bourhis' model examines the ways the context of the acculturation experience is impacted by the setting in which it takes place. Just as Berry's model addresses the reality that minority groups often hold less power in a society and are not given the space to allow their agency to determine the immigrant orientation of their choosing, Bourhis too addresses this dilemma in his model. He names this ability, or inability of immigrant to make their orientation choices with autonomy 'vitality'. An immigrant group's vitality is the measure to which they are permitted by the host society, given the power structures at play, to determine their own acceptance (Bourhis, 1997). For example, when using group vitality as a conceptual framework to compare the relative strength and weakness of immigrant and host groups, a possible outcome could be that a racialized group, different than the majority, has lower vitality and therefore less 
autonomy in determining whether they are accepted by the host. A group with low vitality may present with a desire to assimilate or integrate but be unable to do so because the larger society does not permit their inclusion.

The easily interpretable nature of the IAM model paired with its ability to include enough nuance to consider the major acculturation stressors identified by the literature is the reason this model was chosen for this paper. The belief is that it will allow the researcher to determine the host orientation, as it is represented online, of International Student Centers as it provides a usable framework for isolating the orientation of the host society.

\section{Overview of the Present Study}

Most of the research on international students focuses on mitigating the acculturation stress they tend to experience through behaviour modification (Burger, 2018; Cantwell, 2015; Gregory, 2018; Lee, 2007). Instead, this paper uses Bourhis' Interactive Acculturation Model (IAM) to analyse the type(s) of dominant host acculturation orientation(s) espoused by the International Student Services Offices at the University of Toronto, York University, and Ryerson University through their International Student Services webpages. The multilevel structure of the IAM model will also allow the researcher to consider the multiple spheres in which the students exist: macro level government policy, the city in which the university is located, their experience on campus. It will also show how the International Student Services offices can be impacted by those spheres and to what degree they aim to connect students to communities outside of campus. Specific word use in describing programming on each university's International Student Services page will also be compared. The findings of this paper could be of interest to universities and government policy makers seeking to better understand and ameliorate the experience of Canada's international students. 


\section{Methods}

A thematic analysis was conducted, using Bourhis' IAM model to answer the research question, what are the acculturation orientations of International Student Services Websites at the University of Toronto, York University, and Ryerson University. The research question was generated after a review of the literature surrounding the rise of international education in Canada. To guide this analysis, the researcher followed a thematic constructionist approach to capture important content from the data that could be used to respond to this question. After the coding process five key themes were identified based on their prevalence in the data and their utility in answering the research question (Braun and Clark, 2006).

\section{Data collection}

During the first full week of the fall semester in 2019, all data contained on the International Student Services web sites of Ryerson University, York University, and the University of Toronto was captured and stored in separate MS Word documents. The table below depicts data as of [2018] on how many international students attend the universities in question, and therefore how many international students are being served by each university's International Student Services Website.

\begin{tabular}{|l|l|l|l|}
\hline & University of Toronto & York University & Ryerson University \\
\hline Undergraduate & $\begin{array}{l}\text { 2018-2019 } 22 \% \text { of } \\
\text { undergraduate were } \\
\text { international students }\end{array}$ & $\begin{array}{l}\text { 55,700 students of } \\
\text { which 8,500 or } \\
15.3 \% \text { were } \\
\text { international students }\end{array}$ & $\begin{array}{l}\text { (2017-2018): 32,302 } \\
\text { full time students of } \\
\text { which 1,588 or 5\% } \\
\text { were international } \\
\text { students }\end{array}$ \\
\hline Graduate & $\begin{array}{l}\text { 2018-2019 18.2\% of } \\
\text { graduate students } \\
\text { were international } \\
\text { students }\end{array}$ & N/A & $\begin{array}{l}\text { Ryerson (2017- } \\
\text { 2018): 2,187 full time } \\
\text { students of which 297 } \\
\text { or } \\
7.3 \% \text { were } \\
\text { international students }\end{array}$ \\
\hline
\end{tabular}


Isolating the International Student Services page from the broader university website pages was not a straight forward process. For example, using Google Search Engine to locate resources for international students did not always take the researcher to the home page of the International student website for each of the universities in question. All three universities' post recruitment and promotional materials aimed directly at international students and searching for international student support sometimes led to these recruitment pages. However, it was important to determine and maintain parameters around the International Student Services site for the replicability of the study. As the recruitment pages fall outside of the scope of this paper their content was not included in the analysis.

Instead of searching for the support services available for international students in a search engine, the researcher searched for the International Student Services home page of each of the universities in question. These sites served as the starting point for document collection as the researcher followed the web designers' flow of pages, recording their primary and secondary pages using MS Word's bulleted navigation pane to sort the information flow.

The resulting MS Word documents which were created for each university were searchable for key words allowing the researcher to easily locate word use and review individual sections of the website. For example, the researcher was interested in determining how many different ways the word 'culture' was used on each site. MS Word's search function made this type of inquiry easily accomplished by isolating the query and making all instances of its use visible on the left side by search panel.

While the majority of the data collected from the International Student Services sites was extracted from data on pages located under each university's International Students Services web pages, there were occasions when the data linked to other sites, linked to services outside of 
online content aimed directly at international students. When the information was no longer directly below an information flow path that could be traced back to the International student site it was excluded. Reference to the availability of this information through an external source, however, was noted through the inclusion of the link that led to this external information.

Audio visual files have not been downloaded but screen shots of the links to these files were saved and are accessible through their original links. They were included in the analysis if their publication dates on the various platforms remained constant.

\section{Coding}

Once the data was collected the material found within each university's webpage was read through several times. Once the researcher was familiar with the material on each of the University's International Student Services sites, it became possible to compare and contrast the material and in doing so develop dichotomous inclusion/exclusion codes. After examining the materials on the web pages the researcher would refer back to notes taken from a close reading of Bourhis' IAM model specifically focusing on the Dominant Host Majority Orientations section. This loop of reading the material on the International Student Web pages, and rereading the IAM model allowed the researcher to operationalize the five host orientations through a symbiotic process.

\section{Operationalising Bourhis' Dominant Host Majority Acculturation Orientations}

This section discusses how each orientation was operationalized and eventually turned into the discrete codes appearing in Table 1.

Integration: Post-secondary institutes will provide opportunities for international students to learn about Canadian culture while celebrating and fostering learning opportunities for Canadian students to learn from the international students. The post-secondary institute will 
provide both time and space for these interactions to occur. For instance, this may take the form of the school providing clubs and spaces on campus for host nationals and international students to meet and learn from each other. In desiring to maintain a space for international students to maintain a connection to their heritage culture, there might also be some clubs where international students can connect with other students that share their heritage culture. The school may also provide information on immigration avenues open to international students so that they can pursue a path to Canadian citizenship and will look for ways of connecting international student to the broader city and community in which the University is located.

Assimilation: International students will be given opportunities to learn from and then emulate host nationals. For instance, this may take the form of the post- secondary institute providing cultural information sessions, encouraging international students to learn English and to communicate in the same ways as host nationals. International students who relinquish ties to their heritage culture will be encouraged to seek avenues for permanent immigration.

Segregation: Post-Secondary Institutions will allow international students to enroll as students but will likely provide separate spaces and services for them. This may take the form of international students attending classes on a separate campus or only receiving instruction on satellite campuses in their country of origin. This orientation would also mean that international students could only attend clubs with other international students. Under a segregationist approach English and French students would likely be the only languages taught at the schools and other host national students would not be permitted to learn about the culture or language of international students.

Exclusion: Post-Secondary Institutions would not permit international students to enroll. 
Individualism: Post-Secondary Institutes would not have an International Student

Website. The students would be permitted on campus but would be expected to access the same supports as all other students.

\section{Themes}

Once the codes were created through a joint process of reading the content of the websites while reviewing Bourhis' model, the themes were built. The researcher developed an application of Bourhis' model in which post-secondary institutes serve as a staging ground for the Host Orientations described in the model. Coding and then organizing the data into themes allowed a thematic analysis to be conducted in which the researcher determined the type of dominant host majority orientation espoused by each university.

\section{Results and Discussion}

A review of data revealed five themes and seventeen codes. These are defined in Table 1.

In the paragraphs below, I define each of the five themes and corresponding codes discussing how each interacts with the literature surrounding international students and the dominant host orientations found in Bourhis' IAM model (refer to Figure 1). There will be times when different orientations are found within the same theme but an overall recommendation on which theme is most prominently held to by each university is found within the conclusion.

\section{Theme 1: Connecting International Student to each other and/or Canadian Students}

This theme generally concerned the ways International Student Services Websites did or did not create avenues for international students to get to know each other as well as the broader student population. There are eight codes in this theme and each is discussed below.

1a) A separate international student orientation provides additional support for international students so they can better navigate the general orientation that they are also 
welcome to attend. All three universities encouraged international students to attend an orientation created specifically for them, in addition to the general orientation. Had the international students only been invited to attend the international student orientation and not the general orientation their individualised orientation may have been evidence of a dominant host majority acculturation orientation of segregation. However, since international students are encouraged to attend both of the orientations this is not the case. Likewise, had the separate orientations for international students tried to teach international students to act like Canadians instead of providing tips on intercultural communication, which included awareness building of their own cultural communication patters, these separate orientations would have been evidence of a dominant host majority acculturation orientation of assimilation.

None of the three universities share all of their orientation materials on their web sites; however, the material that they do share shows no evidence of requiring students to abandon their heritage cultures. Instead, the orientation materials shared on the websites contain phrases like, Intercultural adaptation, suggesting a dominant host acculturation orientation of integration. The word choice of, 'intercultural' implies that many cultures are encouraged to practice communicating between themselves without becoming exactly like one another. As the University of Toronto's website states, intercultural experience is “about the meeting of different people, languages, traditions, values and ways of interpreting the world" (University of Toronto). As Bourhis' model indicates, this encouragement towards international students and domestic students to work towards a biculturalism that allows individuals to have cultural fluency in more than their heritage culture is promoted in the integration approach and put into practice in the ways the universities are running their international student orientations. 


\section{1b) Provides online liaison to answer questions virtually (notes nationality of each}

liaison and the languages they speak). York University is the only university to offer this service. Through their program, Global Connections, they hope to help their new international students find the information they need about both York University and Canada prior to arrival. The program accomplishes this, "by connecting new international students with current international students called Global Student Liaisons (GSL), this new program bridges the gap across countries, languages, and time zones.”( http://yorkinternational.yorku.ca/internationalstudent-support/). This Global Connections program is unique in that it offers pre-arrival information through individual one-on-one connection to an advisor who may speak the international student's first language and share their nationality. This is done by providing ten global liaison officers from six different countries: India, Malaysia, Turkey, Ukraine, The Philippines, and Rwanda. This service is an example of a university demonstrating a dominant host majority acculturation orientation of integration. This enables international students to select any advisor that they wish, but presumably allowing most to choose someone who might best understand the context which they are coming from in addition to the context in which they will soon be entering. Further, York University is demonstrating a belief that someone who is not Canadian can serve as an expert on acculturating to Canadian culture- something that a dominant host acculturation orientation other than integration would not permit. In line with the biculturalism celebrated in Bourhis' host integration orientation, the advisors' ongoing ties to their heritage culture are highlighted as advantages, and do not diminish their standing as someone who is able to navigate and interact with mainstream culture as these ties are not seen to diminish their ability to thrive in the culture within which they are now situated. 
1c) Provides Peer Mentor Program specifically for international student. Without analysing the content of the information mentors cover during mentorship meetings, it is not possible to draw conclusions on whether the peer mentorship program fits within a dominant host majority acculturation orientation of integration, assimilation or individualism. However, the structure of the mentorship programs offers some clues. The University of Toronto and York University both offer peer mentorship programs exclusively for international students. Ryerson University's model is different in that it provides peer mentors for all students and does not have a particular program geared towards international students. Ryerson University's individualist approach to peer mentorship may make their program fit within Bourhis' individualism host attitude in which the international student is treated just like any other student, regardless of their country of citizenship.

The universities also promote their mentorship programs in different ways. In a promotion video, Ryerson University notes that their program is "not about assimilation but about finding the community you fit into" (Ryerson University, 2019). The University of Toronto's mentorship program's goal is to create an intercultural learning opportunity by pairing each mentee with a mentor from another culture. And while York University does not specifically name the goal of its mentorship program it does note that, "The International Student and Scholar Services team support international student retention and success by offering expert non-academic programs and services, and by fostering a dynamic global community" (York University, 2019).

1d) Provides Personalized acculturation support through a one on one meeting with an advisor (separate from government focused immigration advice). York University and Ryerson University each offer one on one appointments for international students to meet with 
staff who are able to assist with courses, language acquisition, and immigration matters. The University of Toronto's personalized meetings seem to offer more in the ways of acculturation support as their transition advisors provide the following support:

"1.Adjust to Canada - Learn how to form friendships in Canada, succeed in the U of T classroom, live in Toronto's climate or deal with feeling homesick.

2.Build your new community - Get involved on- and off-campus, find groups and sign up for activities.

3.Make a plan - Achieve your goals during your time here at the University of Toronto.

4.Find help when you need it - Get access to helpful programs, services and information" (University of Toronto, 2019).

The types of support indicated above suggest a dominant host majority acculturation orientation of integration as the list forming friendships in Canada, as well as building communities on and off campus refer to friendships that are not solely with other international students. We can infer that it is not segregation because the purpose of the meetings is to help the international students succeed within the Canadian context.

\section{1e) Information provided on a broad range of student clubs that international}

students are welcome to join. Only the University of Toronto provides links to the student clubs available to all students within their International Student Services Webpages. Given the scope of this analysis, which limits research to the international student pages of each university, it is possible that additional information is available on different sections of the university's website, which will not be referenced or reviewed. It can however be inferred that the University of Toronto believes that the ability of international students to join mainstream campus clubs is important enough to put on their international services web page, suggesting a dominant host 
majority cultural orientation of integration as the listed clubs reflect the diversity of the universities' multicultural student body.

1f) Intentional time and space devoted to cross cultural conversation or activity. The willingness of all three universities to devote time and resources to cross cultural conversations is a strong sign of a dominant host acculturation orientation of integration as it creates opportunities for international students to learn about and interact with Canadian culture(s) without abandoning their own cultural practices thereby embracing an integration orientation. Each university runs a regularly scheduled drop in time in which both international and domestic students are encouraged to spend time with one another. The University of Toronto's club is called Global Local. Ryerson University has a similar club named Glocal and York University has a drop-in time for students called, the Global Café. The University of Toronto also runs a Global Citizenship Certificate program. The Global Citizenship Certification program is designed to prepare both domestic and international students, "for working and succeeding in a culturally diverse and rapidly changing world" (University of Toronto, 2019). To complete the certificate, students attend workshops, intercultural experiences, and co-curricular activities.

Even the ways in which two of the three universities have chosen to structure their webpages has created a cross-cultural point of connection. Both York University and the University of Toronto have chosen to house their International Student web pages within a section of their website that also houses information for their domestic students who are returning from or seeking international work or study placements. This pairing of acculturation services for both domestic students going abroad and international students adjusting to the Canadian context normalizes the acculturation process and removes the stigma of needing support by not solely targeting international students. 
Each intercultural club has very similar descriptions suggesting common purposes. The descriptions for the clubs as they appear within the International Student Services Webpages appear below:

Ryerson University's Glocal Club: "is an intercultural dialogue program that provides students with the opportunity to connect across differences and similarities. This program promotes acceptance and appreciation of different cultures and the capacity to function interdependently with people from different cultural backgrounds" (Ryerson University, 2019).

The University of Toronto's Global Local objectives are: “To enrich ideas on acceptance, appreciation, empathy of diverse others. To appraise their own cultural values and that of others. To enjoy learning about the experience of diverse others. To become more aware and understand your own perspective better. And to increase intercultural awareness for a competitive advantage in the global workforce" (University of Toronto, 2019).

York University's Global café is: "the space for international and domestic students from across programs, Faculties, countries, and cultures to meet and get to know each other! All YorkU students and faculty are welcome to attend. Through Glocal Links, you will enrich your ideas on appreciation, empathy toward different cultural backgrounds and build self-reflect. Our aim is to create culturally competent global citizens at Ryerson University. This program does not only benefit international students, ALL Ryerson students are invited and encouraged to participate and celebrate diverse perspectives" (York University, 2019).

1g) Explicitly English language learning program. The University of Toronto is the only one of the three Universities to provide links to their English language supports for EAL learnings on their international student website. 
The University of Toronto International Student Services site also provides a written component to its English support by providing individual web pages devoted to each of the following topics with the stated purpose of helping the learner to, "navigate University and city interactions in English" (University of Toronto, 2019). The English Language Topics selected by the university to provide additional information cover a broad range of situations, including communicating with professors and teaching assistants, talking with other students and the vocabulary needed for specific tasks like banking or accessing health services.

Ryerson and York Universities do not provide English Language supports linked to their international student websites. York does provide a distress response in languages other than English and French- a service which is listed on its website. While the University of Toronto's International Student Services site provides the most guidance on language learning it is also the least accessible to EAL learners. Compared to York University and Ryerson University, the University of Toronto's entire International Student Services site uses less graphics, and offers denser written content that requires a higher level of English to comprehend.

1h) Language exchange group. As the name suggests, this program encourages students with knowledge of one language and a desire to learn a different language to spend time with one another taking turns teaching and learning one another's languages. The University of Toronto is the only school linking this club to their international student page. The desire to provide host and international students with the opportunity to learn each other's languages falls into the integration dominant host majority acculturation orientation. Richard Levin, the current executive director of enrolment services at the University of Toronto notes that, "We have been putting effort into recruiting around the globe, as we do domestically, so I think we're seeing 
some of that paying off." And that, "It's important that the university provides a really good experience for international students if we want to continue to recruit them" (Crawley, 2017).

\section{Theme 2: State Immigration Policies As They Pertain to International Students}

This theme generally concerns whether the universities show an awareness, leverage, or are limited by the state immigration policies that pertain to international students. There are four codes under this theme and each are discussed below.

2a) Links to study permit explanations and support. The University of Toronto, Ryerson University, and York University all prominently advertise their willingness to advise and assist their international students as they navigate the parameters of their study permits. The willingness of the Federal Government to work with the universities, along with other Designated Learning Institutes, by providing these permits demonstrates that the Federal Government, in partnership with Canadian universities, is keen to continue recruiting international students. As short-term residents, international students support the local economy, increase the funding resources of universities, and bring an internationalism into the classroom.

Permitting international students to attend Canadian universities is also a way for the Canadian government to partner with universities to secure funding outside of the traditional avenue of the state coffers and domestic student fees that are set by the Province. Permitting international students' entry to Canada in order to attend school is also an act which knowingly exposes citizens to experiences of the 'other.' This rules out macro level dominant host acculturation orientations of segregation and exclusion as a state who held one of these views would not want their citizens to attend classes with these non-Canadians. If International students do choose to remain in the country long term, it is the university, not the government, which will 
have provided their acculturation services. The university however, does receive compensation for this service through international student fees.

\section{2b) Provides links to IRCC and permanent residency options. The Canadian}

government's willingness to provide pathways to citizenship for international students is evident in the programs that they create to retain these students. In turn, the universities leverage these programs and make them a part of their own program's marketing pitch by sharing the immigration pathway information with their international students. If they graduate from a designated learning institute in Ontario they are eligible to apply for a Canadian Post-Graduate Work Permit (PGWP). This Canadian work experience increases an applicant's chance of securing permanent residency through the points system of immigration. This willingness to enable international students to follow a pathway to citizenship is an example of the country of Canada having a desire to integrate people from around the world into its citizenry, which is evidence of what Bourhis model terms an integration policy centered on pluralism.

The IAM model creates a helpful visualization of the flow of how state policies are developed in tandem with a society's orientation towards immigrants (Bourhis, 1997). The visualization helps to get around the proverbial chicken or the egg argument of whether policies arise out of reality or if they are shaped by reality. The IAM's bi directional information flow shows that policies feed into reality and that reality feeds into policies.

2c) Specifically mentions Post-Graduate Work Permits (PGWPs). Universities may leverage pre-existing government immigration programs as recruitment incentives which result from completion of a degree at each of the universities. The University of Toronto, York, and Ryerson all provide avenues to potentially securing Canadian citizenship- arguably an increasingly commodified and highly sought resource. In 2019, Ryerson University made 
attending a PGWP Immigrations Insights Workshop a mandatory activity which must be completed before an international student is permitted to request their letter of completion from International Student Services (Ryerson University, 2019). The mandatory nature of this session shows that pathway to citizenship could be considered to be an integral part of the international student experience at Ryerson.

2d) Provides accredited immigration consultants. The University of Toronto provides written links describing work permits, study permits, and permanent residency but do not offer one on one counselling with accredited immigration consultants. In offering a dedicated professional to assist its students in seeking permanent resettlement in Canada, York University and Ryerson University are enacting a dominant host orientation of integration or assimilation depending on the manner in which the subject is covered. However, given the breadth of the intercultural supports each university provides, their provision of settlement services is most likely demonstrative of an integration orientation.

\section{Theme 3: How are potential problems acknowledged and/or addressed?}

This theme looks for evidence of the universities warning students that they may face challenges or providing them with advice on how to respond if they do face challenges. There are two codes under this theme. Each are discussed below.

\section{3a) Is the word 'challenge' used when referring to transitions or cultural}

adaptation. All three of the universities acknowledge that international students may face some acculturation challenges like loneliness, difficulties in adjusting to new living, and academic environment (Smith and Khawaja 2011, Berger, 2018).

York University stands out amongst the three post-secondary institutions as the university proactively reaching out to international students who may be experiencing acculturation 
challenges that are causing them anxiety without recourse of what to do with their feelings. York University's campaign called \#YIFeel is meant to: initiate a dialogue about mental health among international Students, give them a space to tell their stories, outline how mental health is impacted by cultural differences, and bring the importance of this topic to the forefront (http://yorkinternational.yorku.ca/yifeel/). The campaign includes pictures of international students experiencing different emotions and calls on students to reach out and communicate what they are feeling with one another.

3b) Do the sites talk about racism? None of the three universities discuss discrimination or racism in their International Student Services sections. Most of the references to diversity link to Canada's multiculturalism as a policy that delivers equal treatment to all. As per Ryerson University's website "Canada is a beautiful country known for its multiculturalism, peacefulness, safety and orderliness. Despite this, international students should follow a high level of safety precautions while they pursue their studies and work in Canada" (Ryerson University, 2019). While Ryerson warns that safety precautions do need to be adhered to, all of the universities could do more in preparing international students, specifically, with tools that could be used if they encounter incidents of racism or discrimination which still exist within Canada's multicultural framework (Davis, 2017, Burman, 2016, Bannerji, 2000). As Bourhis' model notes, state policies interact with acculturation orientations but the flow is bi-directional meaning that Universities should make sure that they are creating space for students to share their stories, so that the government, and the university itself is aware of their experiences. 


\section{Theme 4: Connecting to Life Outside of Campus}

This theme generally looks for evidence of ways in which the universities may or may not try to connect students to life occurring outside of the university boundaries or to the contrary. This theme contains two codes. Each are discussed below.

4a) Off campus 'field trips.' All three universities provide their international students with opportunities to explore Toronto, and other parts of Canada through tours marketed specifically to international students. The local tours of Toronto neighbourhoods are free and are usually led by other students whereas the further afield tours come at a cost and are led by outside tour groups that are promoted by the university. York University promotes the services of a tour company, ISX which is described as, "a leading international student tour operator that fosters multicultural travel experiences within Canada and the United States" (York University, 2019). Ryerson includes both a campus and city of Toronto tour in its international student orientation- clearly encouraging students to partake of life both on and off campus. Likewise, the term 'multicultural travel' by York University lends itself to an integration orientation.

4b) Is Toronto's diversity marketed? In Canada, the phrase 'multiculturalism' has become such a commonly used phrase that it is tied to the country's brand, and it is referred to by politicians as one of the country's greatest strengths. This branding is exemplified by the motto of the city of Toronto, "Diversity our strength." All three universities market Toronto's diversity by naming it as a reason why international students will feel comfortable on their campuses. In doing so, all three are in essence marketing Canada's Pluralism Ideology, which is referenced in Bourhis' model as a type of state integration policy which impacts the dominant host orientation (Bourhis, 1997). 
Diversity implies difference and the celebration of difference is found only within the integration orientation so this is a further example of the International Student Services sites holding an integration orientation.

\section{Theme 5: Other}

This theme is a place where codes that did not fit under other themes are located. There is only one code supporting this theme and it is discussed below.

5a) Are academic awards/bursaries available to International students? The University of Toronto, York University and Ryerson University are all publicly funded institutions. As such, they receive money from the Provincial Government to support their operating costs. While all of these post-secondary institutions note that diversity, increased intercultural awareness or cross-cultural skills in a global world, are leading reasons for why they want to have International students attend classes on their campuses, as previously noted both the Federal Government and each university makes clear that there is also an economic benefit to the inclusion of international students. The University of Toronto does not provide academic awards or bursaries to their international students while York University and Ryerson University do. The University of Toronto makes this funding structure known to its international students on the international student web page, "The University of Toronto is a publicly-funded institution and because of that cannot offer financial aid to international students. If you are an international applicant, you should find out about your home country's financial aid programs to see if you qualify for assistance" (University of Toronto, 2019). It does not list any scholarships for international students on its website.

This code was chosen as it speaks to the longer term "value" of international students. If international students are seen as more than sources of funding, and instead as future Canadians, 
it is possible that they may be deemed to also be deserving of financial assistance if they would otherwise be unable to finish their degrees or simply as reward for excellence. Both Ryerson and York provide scholarship opportunities for international students. Their decision to do so may be evidence of University leadership believing in Pluralism ideology. International students, the quintessential "other" due to their lack of permanence in the country, are seen as people worthy of financial investment regardless of their country of citizenship. Or, it is possible that this is also evidence of a belief in global citizenship which would fall outside of Bourhis' model, or out of a belief that international student may eventually become citizens.

Unlike the University of Toronto, Ryerson University seems to tie the possibility of the longer-term resettlement of international students in Canada into its scholarship structure. The Salad King restaurant, which is located across the street from the campus, established the award because the owner, Mr. Liu, "recalls the challenges that he faced as an international student in a new country. The Liu family recognizes that some Ryerson international students overcome similar difficulties and financial burdens in their transition to Ryerson University and life in Canada, and achieve tremendous success" (Ryerson University, 2019). Ryerson University also provides another scholarship available exclusively to international students in partnership with Scotia bank. The scholarship notes that its purpose is to, "enhance and contribute to the cultural and ethnic diversity of Ryerson and the greater Toronto communities" (Ryerson University, 2019). In providing these awards Ryerson University states that it "wants to demonstrate support for international students and encourage success in their academic life" (Ryerson University, 2019). In addition to these two scholarships, Ryerson University provides one-time emergency bursaries to international students who experience a crisis. In doing so they state that, “International Student Support (ISS) realizes how important financial assistance is for any 
international student who may be faced with unexpected financial difficulty" (Ryerson University, 2019).

Similar to Ryerson University, York University also provides scholarships and bursaries to its undergraduate and graduate international students but it provides them at a higher value. Like the University of Toronto, York University notes that some of its funding is only available to Canadian students yet it still offers eight entrance scholarships in the range of $\$ 1,000-\$ 10,000$ and four awards all valued at over $\$ 15,000$ and awarded to 11-21 students annually. The most significant of these being three International Entrance Scholarships of Distinction valued at $\$ 35,000$ per year renewable for an additional three years if marks are maintained (York University, 2019).

\section{Words Chosen to Describe the Programming of International Student Service Websites}

While not a theme, the words chosen to describe the purpose and programming of International Student Services Websites may be relevant to each university's acculturation orientation. The relevant words are compiled for each university in Figures $2 \mathrm{a}, 2 \mathrm{~b}$, and $2 \mathrm{c}$ which

provide Word Cloud graphics to summarise the findings for each university. The words included in the 'word clouds' were chosen because they imply adherence to different types of dominant host acculturation orientations.

The International Student Services websites for all three universities are difficult to perform a word count on because they link back to the same pages in different ways. For this reason, these Word Cloud graphics do not include a count of how many times a word appears within international student web pages but instead focuses on the different words that were chosen and the different ways in which they were used. The size of the words appearing in the word cloud is not weighted. The word clouds illustrate all of the different ways the following 
words were or were not used: diversity, culture, global citizenship, intercultural, integration or acculturation, assimilation, segregation, exclusion, individualism, customs, values. The inclusion of words like diversity or intercultural suggest that each University is intentionally creating an environment in which different cultures are welcome in their entirety and encouraged to participate as members of the student body without needing to discard their heritage cultures and assimilate with the pre-existing student body. Both the existing diversity of the student body already reflective of Canada's pluralism, and the encouragement of new international students to retain their unique cultures so that they can teach and share their perspectives with the host students suggest that each university has an orientation of integration.

\section{Conclusion and Recommendations}

All three universities build their international student programming in conjunction with intercultural learning opportunities for Canadian students who learn from the cultures and perspectives of the international students in their midst. This suggests that the universities are open to the international students changing the character of their campuses. All three universities also provide mentorship programs where the students learn from one another; one provided individualized staff support particularly addressing acculturation and all created intentional time and space for host nationals and international students to learn from each other in a mutually supportive setting. All of these factors fit into Bourhis' dominant host acculturation orientation of integration.

As a best practice, it is important to note that establishing International Student Offices, or web sites devoted to supporting international student experiences is not necessarily indicative of a university holding an integration orientation. As this study did not include a review of how mainstream student service offices, websites or other supports built into the fabric of the 
university, might be applicable to international students, the paper is not claiming that supports for international students do not exist outside of avenues geared specifically to international students. Instead it is cautioning that until mainstream students services are reviewed, it is not known whether they provide services that are applicable and/or accessible to international students.

In Collaboration for Cultural Programming: Engaging Culture Centre, Multicultural Affairs, and Student Activities Offices as Partners, Patton and Hannon caution that the establishment of international student offices may not be representative of institutions' willingness to make the needed changes to create university experiences that are truly accessible to all. They advise that international student supports should be integrated into all programming: "multicultural affairs professionals should work with allies throughout campus to ensure that diversity is woven into the fabric of the institution - including policies, human resources, programming, and curricula" (Shuford and Palmer, 2004 as quoted in Patton and Hannon). A separate study could determine whether the University of Toronto, York University, and Ryerson University already do this. It is also worth noting that while all levels of a University should work on inclusion, the benefit of having a centralized point of support for international students is that it can help to mitigate the confusion and isolation that can arise from feeling lost when first arriving in a new place. Further interviews with students would help Universities decipher if international students are using the international student services website to obtain acculturation related information. How many hits the websites receive in general is not currently known.

As the number of international students in Canada continues to grow, it is increasingly important to have additional studies that focus on the ways in which host institutions can best 
orient themselves to support and nurture international students through their international student websites as well as within their mainstream campus services.

\section{Areas For Further Research}

It is not known if the universities in question are aware of the acculturation orientation that their International Student Services Web sites currently embrace. Interviewing the international student staff at each university as well as determining their qualifications would help to understand how each university has reached the same acculturation orientation. It would also be worth exploring what cross sector organizations connect the international student services sector and thereby better understand how this sector informs its policy makers as they develop new services for their students.

To fully apply Bourhis' acculturation model to the experience of international students, the acculturation orientation of international students themselves needs to be studied. If this is done, future research could then compare the host and international student acculturation orientation to determine which of Bourhis' five acculturation outcomes are experienced by the majority of those students.

During this study the researcher frequently had to work at maintaining a separation between the International Student Services Webpages and the International Recruitment Webpages. It does not appear that any research has been done on the recruitment practices of Canada's Designated Learning Institutes as they compete to attract international students. Analysing the recruitment pages is especially relevant as the Canadian government has recently announced additional funding to its international presence and role in recruiting international students for the country's Designated Learning Institutes (Government of Canada, 2018). 
Last, since increasing numbers of international students are becoming permanent residents in Canada, it would be important for policy makers to understand whether the acculturation experience of immigrants who enter the country as international students and then apply for permanent residency through the International Experience class differs from immigrants who enter the country initially through other categories. The differences in these two immigrant groups' experiences might allow us to isolate the role that the experience of attending a Canadian University plays in acculturation and whether some of the Universities' services could be emulated by the government as they create services for the broader class of Canadian immigrants. 


\section{Appendices Figures and Tables}

\section{Figure 1 Bourhis' model}

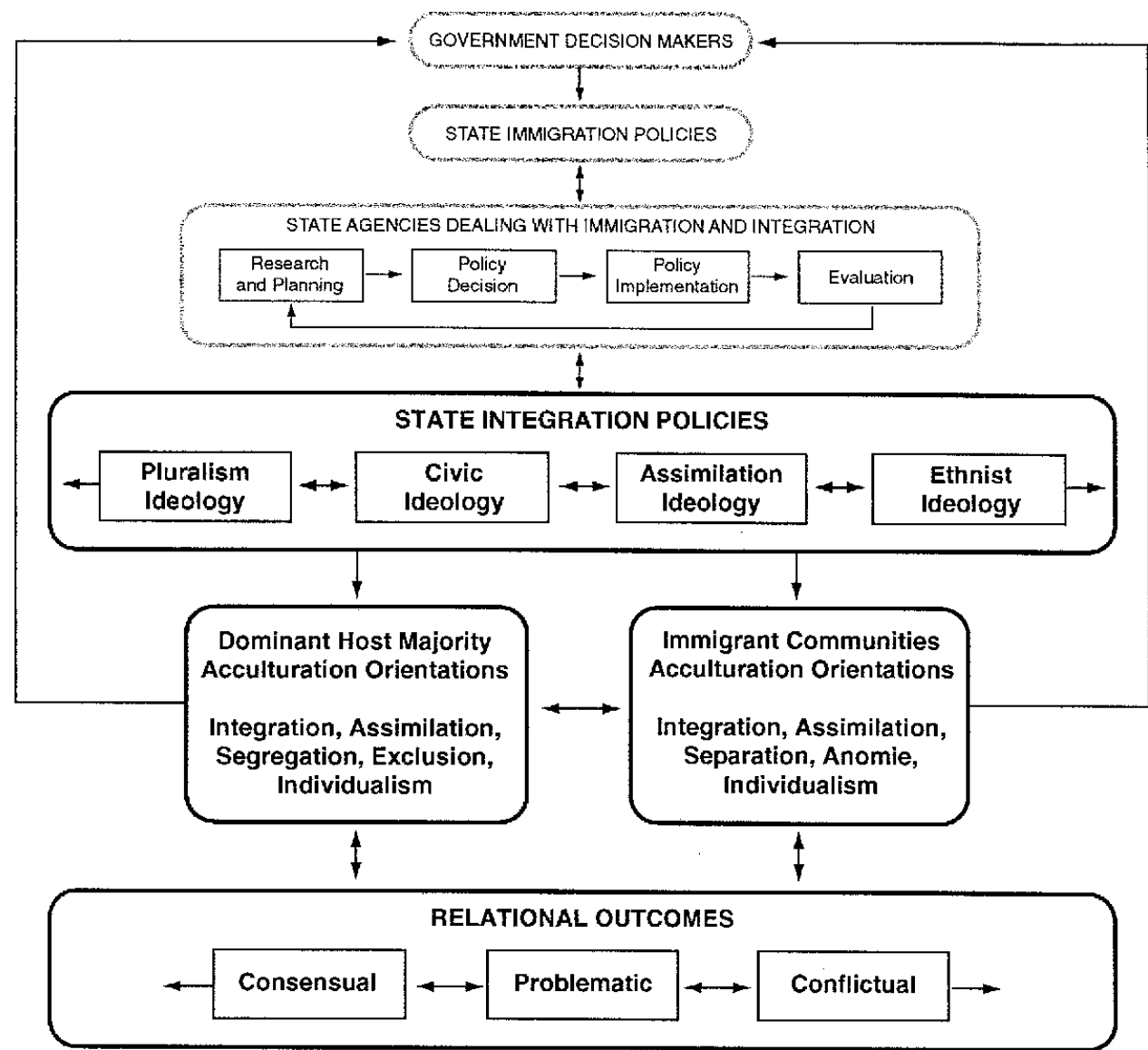


Figure 2a) Ryerson University

\section{Canadian culture}

your own culture

International Student Support \& Intercultural Learning

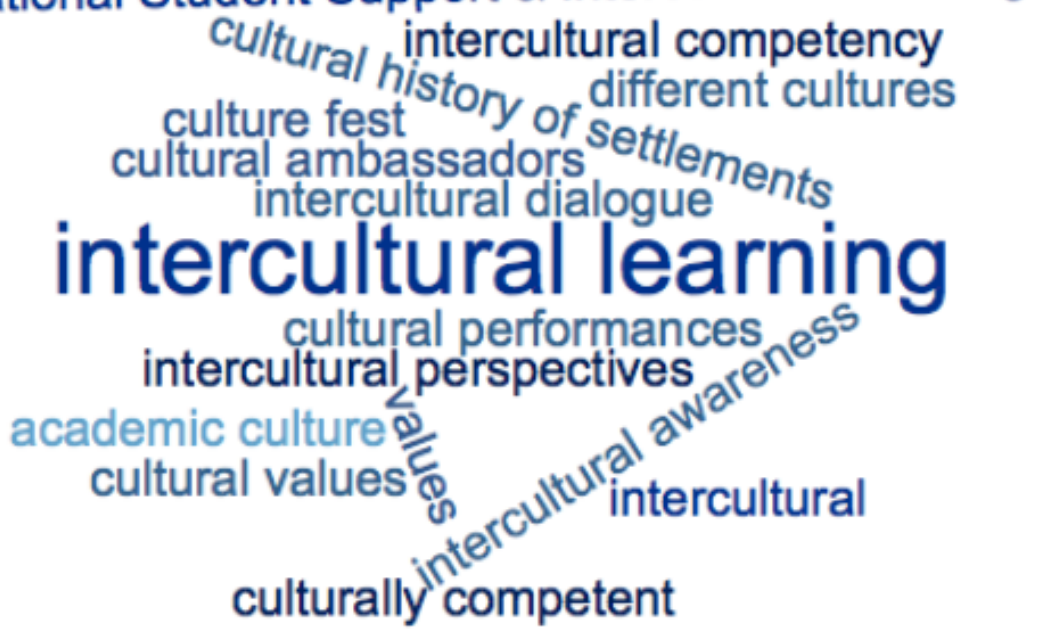

Figure 2b) University of Toronto

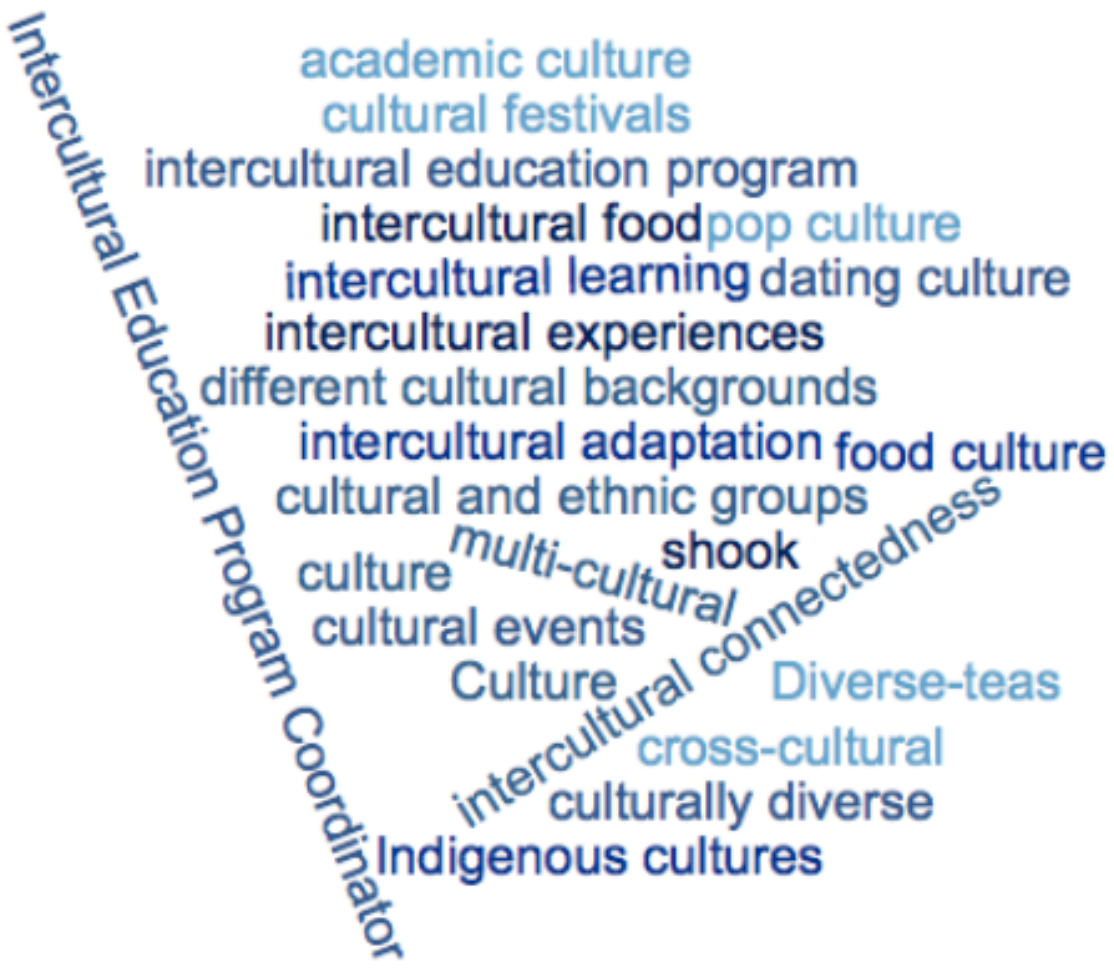


Figure 2c) York University

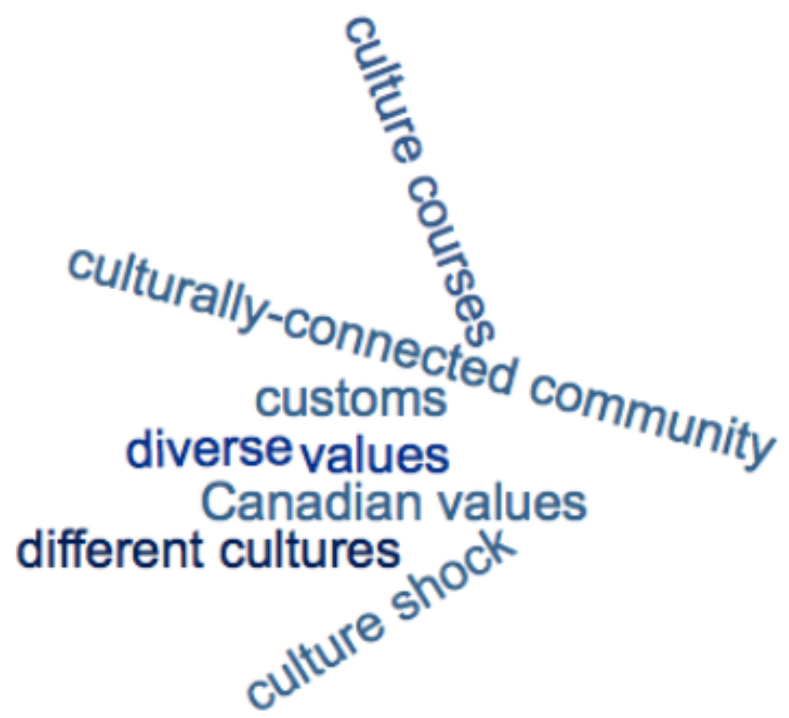


Table 1

\begin{tabular}{|c|c|c|c|c|}
\hline $\begin{array}{l}\text { Host Majority Acculturation } \\
\text { Orientation as reflected by University } \\
\text { programming/ resources or information } \\
\text { specifically developed for International } \\
\text { students and provided to them on the } \\
\text { International Student Services Page of } \\
\text { each University }\end{array}$ & $\begin{array}{l}\text { Type of Host Orientation } \\
\text { indicated (options are } \\
\text { Integration, Assimilation, } \\
\text { Segregation, Individualism) } \\
\text { *Exclusion would not permit } \\
\text { international students to attend } \\
\text { Canadian Universities) } \\
\end{array}$ & $\begin{array}{l}\text { University } \\
\text { of Toronto }\end{array}$ & $\begin{array}{l}\text { Ryerson } \\
\text { University }\end{array}$ & $\begin{array}{l}\text { York } \\
\text { University }\end{array}$ \\
\hline \multicolumn{5}{|l|}{$\begin{array}{l}\text { Theme 1: Connecting International } \\
\text { students to each other and/ and or } \\
\text { Canadian students }\end{array}$} \\
\hline $\begin{array}{l}\text { A separate international student } \\
\text { orientation provides additional support for } \\
\text { international students so they can better } \\
\text { navigate the general orientation that they } \\
\text { are also welcome to attend. }\end{array}$ & Integration & Yes & Yes & Yes \\
\hline $\begin{array}{l}\text { Provides online liaison to answer } \\
\text { questions virtually (notes nationality of } \\
\text { each liaison and the languages they } \\
\text { speak). }\end{array}$ & Integration & No & No & Yes \\
\hline $\begin{array}{l}\text { Provides Peer Mentor Program } \\
\text { specifically for international student. }\end{array}$ & Integration & Yes & No & Yes \\
\hline $\begin{array}{l}\text { Provides Personalized acculturation } \\
\text { support through a one on one meeting } \\
\text { with an advisor (separate from } \\
\text { government focused immigration advice). }\end{array}$ & $\begin{array}{l}\text { Integration given the types of } \\
\text { support provided }\end{array}$ & Yes & No & No \\
\hline $\begin{array}{l}\text { Information provided on a broad range of } \\
\text { student clubs that international students } \\
\text { are welcome to join. }\end{array}$ & Integration & Yes & No & Yes \\
\hline $\begin{array}{l}\text { Intentional time and space devoted to } \\
\text { cross cultural conversation or activity. }\end{array}$ & Integration & Yes & Yes & Yes \\
\hline $\begin{array}{l}\text { Explicitly English language learning } \\
\text { program. }\end{array}$ & Integration or Assimilation & Yes & No & No \\
\hline Language exchange group & Integration & Yes & No & No \\
\hline \multicolumn{5}{|l|}{$\begin{array}{l}\text { Theme 2: State Immigration Policies As } \\
\text { They Pertain to International Students }\end{array}$} \\
\hline $\begin{array}{l}\text { Links to study permit explanations and } \\
\text { support. }\end{array}$ & Integration or Assimilation & Yes & Yes & Yes \\
\hline $\begin{array}{l}\text { Provides links to IRCC and permanent } \\
\text { residency options. }\end{array}$ & Integration or Assimilation & Yes & Yes & Yes \\
\hline $\begin{array}{l}\text { Specifically mentions Post-Graduate } \\
\text { Work Permits (PGWPs). }\end{array}$ & Integration or Assimilation & Yes & Yes & Yes \\
\hline $\begin{array}{l}\text { Provides accredited immigration } \\
\text { consultants. }\end{array}$ & Integration or Assimilation & Yes & Yes & Yes \\
\hline $\begin{array}{l}\text { Theme 3: How are potential problems } \\
\text { acknowledged and/or addressed? }\end{array}$ & & & & \\
\hline
\end{tabular}




\begin{tabular}{|c|c|c|c|c|}
\hline $\begin{array}{l}\text { Is the word 'challenge' used when } \\
\text { referring to transitions or cultural } \\
\text { adaptation. }\end{array}$ & Integration & Yes & Yes & Yes \\
\hline Do the sites talk about racism? & $\begin{array}{l}\text { Lack of provision indicates } \\
\text { Individualism although supports } \\
\text { may be available to students in } \\
\text { other parts of the university } \\
\text { websites or in person services }\end{array}$ & No & No & No \\
\hline \multicolumn{5}{|l|}{$\begin{array}{l}\text { Theme 4: Connecting to Life Outside of } \\
\text { Campus }\end{array}$} \\
\hline Off campus "field trips" & Integration & Yes & Yes & Yes \\
\hline Is Toronto's diversity marketed? & Integration & Yes & Yes & Yes \\
\hline \multicolumn{5}{|l|}{ Theme 5: Other } \\
\hline $\begin{array}{l}\text { Are academic awards/bursaries available } \\
\text { to International students? }\end{array}$ & Integration & No & Yes & Yes \\
\hline
\end{tabular}




\section{References}

Altbach, P. (2015). Higher Education and the WTO: Globalization Run Amok. International Higher Education, (23). doi: 10.6017/ihe.2001.23.6593

Atlantic Canada Opportunities Agency (2018). Study and Stay Program. Government of Canada Retrieved on November 10, 2019, from https://www.canada.ca/en/atlantic-canada-opportunities/news/2018/07/study-and-stayprogram.html

Bannerji, H. (2000). Introduction: The dark side of the nation: Essays on multiculturalism, nationalism and gender. Canadian Scholars' Press.1-13.

Bauder, H. (2013). Domicile citizenship, human mobility and territoriality. Progress in Human Geography, 38(1), 91-106. doi: 10.1177/0309132513502281

Berger, R., Safdar, S., Spieß, E., Bekk, M., \& Font, A. (2018). Acculturation of Erasmus students: Using the multidimensional individual difference acculturation model framework. International Journal of Psychology. doi: 10.1002/ijop.12526

Berry, J. W. (1997). Immigration, Acculturation, and Adaptation. Applied Psychology, 46(1), 534. doi: 10.1111/j.1464-0597.1997.tb01087.x

Bourhis, R. Y., Moise, L. C., Perreault, S., \& Senecal, S. (1997). Towards an Interactive Acculturation Model: A Social Psychological Approach. International Journal of Psychology, 32(6), 369-386. doi: 10.1080/002075997400629

Braun, V. \& Clarke, V. (2006). Using thematic analysis in psychology. Qualitative Research in Psychology, 3: 2, 77-101. doi. 10.1191/1478088706qp063oa

Burman, J. (2016). Multicultural feeling, feminist rage, indigenous refusal. Cultural Studies $\leftrightarrow$ Critical Methodologies, 16(4), 361-372. 
Cameron, J.D. (2006). International Student Integration into the Canadian University: A PostWorld War Two Historical Case Study. History of Intellectual Culture 6(1)

Canadian Bureau for International Education (2018). The Student's Voice: National Results of the 2018 CBIE International student Survey. ISBN: 978-1-894129-99-2

Canadian Bureau for International Education (2018). International Students In Canada. ISBN: 978-0-920496-28-2

Cantwell, B. (2019). Are international students cash cows? Examining the relationship between new international undergraduate enrollments and institutional revenue at public colleges and universities in the US. Journal of International Students, 512-525.

Chirkov, V. (2019). An introduction to the theory of sociocultural models. Asian Journal of Social Psychology. doi: 10.1111/ajsp.12381

Chirkov, V. (2009). Critical psychology of acculturation: What do we study and how do we study it, when we investigate acculturation? International Journal of Intercultural Relations, 33(2), 94-105. doi: 10.1016/j.ijintrel.2008.12.004

Citizenship and Immigration Canada (2015). Evaluation of the International Student Program. Evaluation Division. Ci4-53/2015E_PDF 978-0-660-02462-2 Ref. No.: E3-2013

Crawley, M. (2017). Universities growing more reliant on foreign student fees. Canadian Broadcasting Corporation. Retrieved from https://www.cbc.ca/news/canada/toronto/international-students-universities-ontariotuition-1.4199489

Davis, A. (2017). "The Real Toronto": Black Youth Experiences and the Narration of the Multicultural City. Journal of Canadian Studies, 51(3), 725-748. 
Government of Canada External Affairs (1950). Friendly Relations With Overseas Students.

Constitution, May, RG 25, External Affairs, vol. 6502, file 8260-40, Library and Archives Canada [LAC], Ottawa, Ontario.

Government of Canada (2019). Post-Graduation Work Permit Eligibility Requirements. Program Delivery Updates. Retrieved from https://www.canada.ca/en/immigration-refugeescitizenship/corporate/publications-manuals/operational-bulletins-manuals/temporaryresidents/study-permits/post-graduation-work-permitprogram/eligibility.html\#leave_from_studies

Gregory, J. (2018). Integration experiences of international students: A situated case-study. Doctoral thesis, University of Huddersfield. Retrieved from http://eprints.hud.ac.uk/id/eprint/34783/

Immigration Refugee and Citizenship Canada (2019). Canada - Admissions of Permanent Residents with Prior International Mobility Program (IMP) Work Permit Holder Status under Post-Graduate Employment by Province/Territory of Intended Destination and Immigration Category. Government of Canada

Larmer, B. (2008). One of America's Most Vital Exports, Education, Never Goes Abroad, But It Still Faces Threats. The New York Time Magazine. Retrieved from https://www.nytimes.com/2019/01/03/magazine/one-of-americas-most-vital-exportseducation-never-goes-abroad-but-it-still-faces-threats.html

Lee, J. J., \& Rice, C. (2007). Welcome to America? International student perceptions of discrimination. Higher Education, 53(3), 381-409. https://oi.org/10.1007/s10734-0054508-3 
Nyers, P. (2003). Abject Cosmopolitanism: The Politics of Protection in the Anti-Deportation Movement. Third World Quarterly, 24(6), 1069-1093. Retrieved from http://www.jstor.org/stable/3993444

Patton, L. \& Hannon, M.D. (2008). Collaboration for Cultural Programming: Engaging Culture Centers, Multicultural Affairs, and Student Activities Offices as Partners Creating inclusive environments for cross cultural learning and engagement. Washington, DC

Ryerson University (2019). International Student Support. Student Life., Retrieved on September 12, 2019, from https://www.ryerson.ca/studentlife/internationalsupport/

Smith, R.\& Khawaja, N. (2011) A review of the acculturation experiences of international students. International Journal of Intercultural Relations, 35(6), pp. 699-713.

University of Toronto (2019).Centre for International Experience Student Life. Retrieved on Sept 12,2019, from https://www.studentlife.utoronto.ca/cie

University of Toronto (2019). Enrolment Report, Planning and Budget Office. Retrieved from http://www.planningandbudget.utoronto.ca/Assets/Academic+Operations+Digital+Assets /Planning+\$!26+Budget/Enrolment+Report+2018-19.pdf

Ward, C., \& Kus, L. (2012). Back to and beyond Berry’s Basics: The Conceptualization, Operationalization and Classification of Acculturation. International Journal of Intercultural Relations, 36, 472-485. https://doi.org/10.1016/j.ijintrel.2012.02.002

Wiens, M. (2018). York first Canadian university to give 'Dreamers' a chance at a degree. Canadian Broadcasting Corporation. Retrieved on November 1, 2019, from https://www.cbc.ca/news/canada/toronto/canadian-dreamers-york-university-1.4488252 York University. International Students. Retrieved on September 13, 2019, from http://yorkinternational.yorku.ca/international-students/ 
Ziguras, C., \& Law, S. F. (2006). Recruiting international students as skilled migrants: the global 'skills race' as viewed from Australia and Malaysia. Globalisation, Societies and Education, 4(1), 59-76. doi: 10.1080/14767720600555087 